\title{
"Assim, como estas, muitas outras questões interessantes e de actualidade ficarão pairando na dúvida": uma análise de assim como no domínio da junção
}

RESUMO: Propõe-se, a partir de Halliday (1985) e Raible (1992, 2001), que os Padrões interproposicionais de assim distribuam-se em um continuum, configurado entre os usos representativos dos diferentes tipos de interdependência, partindo dos exemplares de relações do domínio da parataxe até os exemplares de relações hipotáticas, passando pelos que estão entre um e outro pólo do continuum. Ilustraremos o trabalho a partir do funcionamento da locução assim como, numa descrição de seu comportamento sintático-semântico no corpus selecionado e numa análise das evidências do processo de mudança linguística, via gramaticalização, que subjaz seu funcionamento como juntor, a fim de apontar o lugar, no continuum, ocupado por esse Padrão.

Palavras-chave: junção; assim como; parataxe; hipotaxe.

\begin{abstract}
Based on Halliday (1985) and Raible (1992, 2001), this paper argues that the interpropositional patterns of assim are distributed in continuum, set within the representative usages of different types of interdependency, from examples of dominant relations of parataxis to examples of hypotatics, covering examples between the poles of the continum. The paper takes as its starting point the function of the phrase assim como, with a description of its syntactic and semantic behavior in the selected corpus and an analysis of evidence of linguistic change through grammaticalization, which infers its function as a connector indicating the position held by this pattern in the continuum.
\end{abstract}

Keywords: linking clauses; assim como; parataxis; hypotatics.

Universidade Estadual Paulista - São José do Rio Preto. E-mail: luciaregiane@bol.com.br. Processo Fapesp 07/07955-5. 


\section{Introdução}

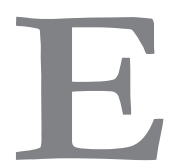

ste trabalho, inserido no Projeto para a História do Português Paulista (Projeto Caipira), tem como objeto de estudo o item assim. Entre os padrões de usos desse item, quatro representam relações interproposicionais, a saber: Padrão A - P, assim Q; Padrão B - P assim como Q; Padrão C - Assim que Q, P; e Padrão D - P, mesmo $\operatorname{assim} \mathrm{Q}$. Neste artigo, interessa-nos descrever e analisar os usos do Padrão B $\mathrm{P}$ assim como $\mathrm{Q}$, no domínio da junção.

Para isso, as ocorrências serão analisadas, na seção 4, segundo critérios formais, a saber: (1) tipo de unidade articulada: palavra, sintagma, oração ou enunciado; (2) co-ocorrência de outro juntor; (3) posição do juntor: inicial, medial ou final; (4) incidência de advérbios; (5) apresentação de formas reduzidas; (6) possibilidade de inversão da ordem; (7) relação entre P e Q: dependência ou não-dependência; (8) entrelaçamento: compartilhamento de estruturas (predicados, sujeitos, complementos etc), e; semântico: (9) relações de sentido.

A partir de Halliday (1985), consideramos que uma dimensão, na interpretação linguística, é o sistema de interdependência ou sistema "tático", considerado geral para todos os complexos - palavras, sintagmas e orações. Assim, o critério (1) fundamenta-se na constatação do complexo específico articulado pelo juntor observado. O critério (2) focaliza o item em seu contexto de ocorrência, levantando implicações referentes ao seu processo de mudança, uma vez que a co-ocorrência de outro juntor é significativa no que tange à gramaticalização ${ }^{1}$ do item, apontando sua não-prototipicidade, naquele contexto, e a necessidade do emprego de outro item já prototípico para a (co)realização das funções pretendidas. Além disso, ajuda a explicar os processos de reinterpretação induzida pelo contexto, de reanálise etc. Os critérios de (3) a (8) depreendem o grau de interdependência entre as orações articuladas pelo juntor e, assim, caracterizam a construção no âmbito da parataxe ou da hipotaxe. Especificamente, os critérios (3) e (4), que colaboram para essa caracterização, relacionam-se, respectivamente, a especificidades da construção

1 A GR será entendida, aqui, a partir da concepção de Traugott (1982, 1989, 1995, 2003), Traugott e König (1991) e Traugott e Heine (1991), entre outros, priorizando a análise dos aspectos semânticos e pragmáticos envolvidos no processo, definido como a pragmatização gradual do significado, que envolve estratégias de caráter inferencial e metafórico. 
no âmbito desses domínios, também no que diz respeito à prototipicalidade ou não do funcionamento desse item na construção e à constituição de contextos importantes para o processo de mudança experimentado.

A justificativa para o grande número de critérios para a identificação de uma mesma característica, relacionada à sistemática de interdependência entre as orações articuladas pelo item observado, encontra-se no fato de que não estamos focalizando apenas construções prototípicas da língua, nos diferentes domínios depreendidos, mas, principalmente, construções não-prototípicas que revelam grande fluidez de traços e não-discritude de relações. Diante disso, um traço não refletido na constatação de um critério poderá refletir-se em outro.

Por sua vez, o critério (9) procurará depreender as relações de sentido veiculadas pelos juntores focalizados em seus vários contextos de ocorrência.

Feita essa descrição, proporemos uma discussão do padrão B - P assim como $\mathrm{Q}$, de uso juntivo em que o item assim se envolve, a partir da análise das relações lógico-semânticas e da interdependência existente entre as porções componentes da oração complexa. Com base em Halliday (1985) e Raible (2001; 1992, apud Kabatek, 2005), interpretaremos, qualitativamente, as relações entre orações articuladas por esse Padrão, em termos dos componentes sintático e lógico-semântico do sistema linguístico. A partir dessa análise, proporemos um continumm parataxe $>$ hipotaxe, em que se localizarão os usos de assim focalizados na descrição de assim como, em relação aos seus outros Padrões interproposicionais.

\section{Material e metodologia}

O corpus organiza-se segundo: (i) as Tradições Discursivas investigadas; ${ }^{2}$ (ii) a delimitação geográfica (Estado de São Paulo); e, (iii) a delimitação tem-

2 O conceito de Tradição Discursiva (TD) nasce, na linguística alemã, fortemente influenciado pela escola de Coseriu que aceita como fundamental, para qualquer estudo da linguagem, a distinção entre três níveis da atividade linguística: universal (equivalente à competência humana de falar em geral); histórico (nível das línguas enquanto sistemas de significação dados e atualizados historicamente); e textual ou dos discursos concretos (abrange o exercício da linguagem por parte do indivíduo). O conceito de TD é definido a partir da reduplicação do nível histórico de Coseriu, i. é, postula-se a existência da língua, como sistema gramatical e léxico, e das TD como dois fatores em nível histórico. Nessa direção, segundo Kabatek (2005, p. 159), "entendemos por Tradição discursiva (TD) a repetição 
poral (séc. XVIII a XXI). Foram analisadas amostras compostas por 274 textos referentes a cada TD, em relação ao:

(A) corpus diacrônico, representativo das TD carta e editorial jornalístico.

O corpus da TD carta divide-se em: (i) Administração Privada: cartas de aldeamento de índios (séc. XVIII e XIX); (ii) Documentos Pessoais: cartas de pessoas relacionadas com: (a) José Bonifácio (primeira metade do séc. XIX); (b) Washington Luiz (fins do séc. XIX); (c) Prof. Fidelino de Figueiredo (fins do séc. XIX e séc. XX); e (iii) Cartas de leitores e redatores de jornais (séc. XIX e $\mathrm{XX}){ }^{3}$

O corpus diacrônico da TD editorial compõe-se por textos do jornal $O$ Estado de S. Paulo desde a sua fundação, quando se intitulava $A$ Província de $S$. Paulo, até 1964, seguindo a divisão: (i) séc. XIX (1875-1895); e (ii) séc. XX $(1858,1859$ e 1864$){ }^{4}$ e

(B) corpus sincrônico, composto por: (i) TD caracterizadas pela oralidade (inquéritos do Banco de dados IBORUNA); e (ii) TD e-mail.

Nessa análise, apresentaremos uma descrição do comportamento sintático-semântico da locução assim como nos corpora selecionados e, a partir dela, evidências do processo de mudança linguística que subjaz seu funcionamento sincrônico como juntor, propondo uma interpretação do processo a partir dos pressupostos teóricos da GR. Trata-se de estudar a emergência de assim como como parte de um mecanismo produtivo de formação de juntores, que vem se consolidando a séculos, a partir da reinterpretação de material linguístico disponível no repertório da língua.

de um texto ou de uma forma textual ou de uma maneira particular de escrever ou de falar que adquire valor de signo próprio (portanto é significável). Pode-se formar em relação com qualquer finalidade de expressão ou com qualquer elemento de conteúdo cuja repetição estabelece um laço entre atualização e tradição [...]" (tradução nossa). Embora não seja o objetivo deste artigo, entendemos que as TD podem influenciar o comportamento e a mudança dos itens focalizados.

3 Esses corpora foram organizados respectivamente por: (a) Simões e Kewitz (2006); (b) Barroso e Batista (2007); e (c) Afrânio Barbosa e Célia Lopes (2002, 2006)

4 Coletado no Centro de Documentação e Apoio à Pesquisa (CEDAP), localizado na UNESP-Assis. 


\section{Fundamentação teórica}

3.1. Sobre a junção de orações

Existem, segundo Halliday (1985, p. 193), duas dimensões sistêmicas na interpretação: (i) o sistema de interdependência (tático), caracterizado pela parataxe e hipotaxe, que é geral para todos os complexos - palavras, grupos, sintagmas e orações; e (ii) o sistema lógico-semântico de expansão e projeção, que é especialmente uma relação inter-oracional - ou melhor, uma relação entre processos, normalmente (mas não sempre) expressa na gramática como um complexo de orações. Essas duas dimensões provêm o modelo funcional de orações complexas na perspectiva desse autor. Lançaremos mão desse modelo para a descrição das relações de junção de orações, estabelecidas por assim como, excluindo unicamente o sistema lógico-semântico de projeção, assim como as considerações sobre encaixamento de orações, visto que esses aspectos não são englobados na análise a partir do item focalizado.

A relação entre orações pode ser interpretada, segundo Halliday (1985, p.194-195) como uma relação de modificação, mas, para isso, esse conceito precisa ser refinado e enriquecido a fim de explicar relações dentro da oração complexa, ou seja, para levar em conta alternativas sistemáticas ao longo de duas dimensões separadas: (i) o tipo de interdependência; e (ii) a relação lógico-semântica.

(i) tipo de interdependência: a relação de modificação, por meio da qual um elemento modifica o outro, não é a única relação que pode ser obtida entre os membros de um complexo. Onde um elemento modifica o outro, o estatuto dos dois é desigual; o elemento modificador é dependente do modificado. Mas dois elementos podem ser unidos em uma colocação igual, na qual um não é dependente do outro (Halliday, 1985, p. 195).

Assim, parataxe é a ligação de elementos de mesmo estatuto, i. é, o elemento inicial e o seguinte são livres, no sentido de que cada um tem seu funcionamento pleno, e bipotaxe é a ligação de elementos de estatutos desiguais, o "elemento dominante é livre, mas o dependente não o é" (Halliday, 1985, p. 198). As orações complexas envolvem relações de ambos os tipos, configurando, tipicamente, uma mistura de sequências paratáticas e hipotáticas em que uma pode estar aninhada dentro da outra. 
A partir dessas considerações, o autor se refere aos membros de um par de orações relacionadas, em parataxe ou hipotaxe, como primárias e secundárias, sendo que a primária é a oração inicial em uma estrutura paratática, e a oração dominante em uma hipotática; a secundária é a oração de continuação em uma estrutura paratática, e a dependente em uma hipotática. ${ }^{5}$

\begin{tabular}{|l|l|l|}
\cline { 2 - 3 } \multicolumn{1}{c|}{} & \multicolumn{1}{c|}{ PRIMÁRIA } & SECUNDÁRIA \\
\hline PARATAXE & 1 (inicial) & 2 (continuação) \\
\hline HIPOTAXE & $\alpha$ (dominante) & $\beta$ (dependente) \\
\hline
\end{tabular}

(ii) relação lógico-semântica: existe um amplo alcance de diferentes relações lógicosemânticas, algumas das quais podem manter-se entre os membros de um nexo oracional primário e secundário. Mas é possível agrupá-las em tipos gerais, baseados em duas relações fundamentais: (1) expansão e (2) projeção (Halliday, 1985, p. 196).

(1) Expansão: a oração secundária expande a oração primária

(a) Elaborando-a (notação $1=2 ; \alpha=\beta$ );

(b) Estendendo-a (notação $1+2 ; \alpha+\beta$ ); ou

(c) Realçando-a (notação $1 \times 2 ; \alpha \times \beta$ ).

Segue uma breve definição de cada uma das categorias da expansão, com exemplos. ${ }^{6}$

(1a) elaboração: uma oração expande a outra, elaborando-a (ou elaborando alguma porção dela); especificando-a com maiores detalhes, comentandoa ou exemplificando-a (ou seja);

(1b) extensão: uma oração expande a outra, acrescentando algum novo elemento, que apresenta, em relação a ela, uma exceção, ou oferecendo a ela uma alternativa $(e, o u)$; ou

Apesar desse aparato para lidar com os membros de um par de orações relacionadas, é importante ter clareza de que o autor não trata os tipos de interdependência entre orações de forma discreta.

6 Os exemplos são os correspondentes em Português daqueles usados por Halliday em Inglês. 
(1c) realce: uma oração expande a outra pelo "embelezamento" em torno dela, qualificando-a com alguma característica circunstancial de tempo, lugar, causa ou condição (assim, já, então).

Em hipotaxe as orações primária e secundária podem ocorrer em qualquer ordem, mas a secundária é sempre a dependente, ou seja, a que faz a expansão ou a projeção. Já em parataxe, somente a ordem 12 é possível. A primária, na relação paratática, é simplesmente uma matéria que vem primeiro. Além disso, como na parataxe não há dependência de um elemento a outro, não há ordenação outra do que aquela que é representada pela sequência. Assim, a ordem é importante e sua inversão representa alterações semânticoformais na estrutura e no significado do complexo. $\mathrm{Na}$ hipotaxe, os elementos são ordenados em dependência, e essa ordenação é amplamente independente da sequência. Consequentemente, têm-se várias sequências: oração dependente (i) seguindo a dominante; (ii) precedendo a dominante; (iii) cercada; ou (iv) cercando a dominante (Halliday, 1985, p. 199-200)

Conjugando à proposta de abordagem das orações complexas de Halliday (1985), uma teoria proposta por Raible (2001; 1992, apud Kabatek, 2005), segundo a qual chama-se junktion a dimensão universal da linguagem que permite a sistematização dos diferentes elementos e técnicas linguísticas usadas para juntar/combinar elementos proposicionais, podemos organizar as técnicas de junção que envolvem o item assim, classificando-as a partir de um esquema sintático-semântico.

Raible descreve diferentes graus do que chama de integraşão e que aqui chamaremos de "interdependência", uma vez que a integração deste autor engloba as formas de interdependência de orações, propostas por Halliday, incluindo, portanto, a parataxe, a hipotaxe e o encaixamento, i. é, desde a justaposição, até formas extremas de interdependência, como a nominalização, passando por etapas de subordinação. Os diferentes graus de interdependência expõem-se em um eixo sintático vertical. A isso, somam-se as diferentes relações semânticas expressas pelos juntores, seguindo uma "escala cognitiva de complexidade crescente". Estamos, portanto, lidando com uma especificação das relações lógico-semânticas propostas por Halliday, que se expõem em um eixo horizontal, como ilustra a adaptação do esquema Junktion, segundo Raible: 


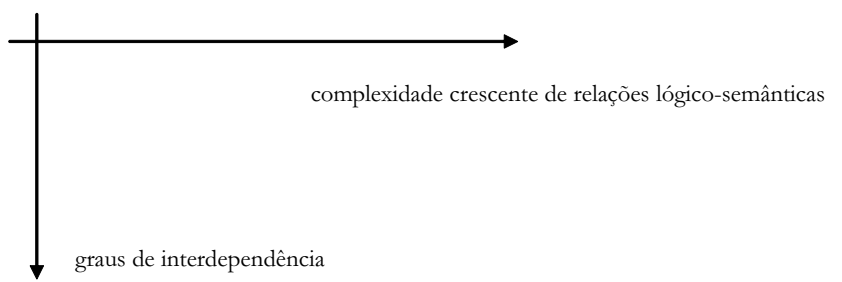

A ordenação dos graus de interdependência dos juntores no eixo vertical pode ser exemplificada a partir do quadro 1, ilustrativo das possibilidades de junção, no eixo sintático:

\begin{tabular}{|c|c|c|}
\hline padrões & tipo de integração & Exemplos \\
\hline $\mathbf{I}$ & $\begin{array}{l}\text { Junção por justaposição } \\
\text { (sem juntor explícito) }\end{array}$ & João está doente. Não come nada. \\
\hline II & $\begin{array}{c}\text { Junção pronominal } \\
\text { (relações dêiticas com a frase anterior) }\end{array}$ & [...] Por isso não come nada. \\
\hline III & $\begin{array}{c}\text { Junção por coordenação } \\
\text { (com juntor explícito) }\end{array}$ & [...] pois não come nada \\
\hline IV & $\begin{array}{l}\text { Junção por subordinação } \\
\text { (hipotaxe e encaixamento) }\end{array}$ & $\begin{array}{c}\text { [...]João está doente porque não come } \\
\text { nada. }\end{array}$ \\
\hline $\mathbf{V}$ & Junção com gerúndios e particípios & {$[\ldots]$ não comendo nada } \\
\hline VI & Junção com grupos preposicionais & [...] Por causa de jejum, João está doente. \\
\hline VII & Junção com preposições & Por fome, João está doente \\
\hline
\end{tabular}

Quadro 1 - Esquema adaptado do eixo vertical de junção (Kabatek, 2005, p. 14)

\subsection{Sobre a relação de comparação}

O Padrão B - P assim como Q caracteriza-se por uma locução que assume comportamentos sintático-semânticos distintos nos nossos corpora. Para iniciar a descrição e análise dessa locução que atua, entre outros, no domínio da comparação, apresentamos algumas características centrais, proposta por Neves (2000), das construçoes comparativas:

(i) do ponto de vista sintático, a interdependência de dois elementos; e

(ii) do ponto de vista semântico, o estabelecimento de um cotejo, ou relação de comparação, entre esses elementos. 
Em consequência de (i), observam-se outras características intrinsecamente relacionadas: o binarismo que encerra os turnos envolvidos na construção; a ordenação em princípio irreversível; a redução do volume do segundo segmento da comparação, via elipse $;^{7}$ e o foco, evocado para explicar os elementos postos em contraste na construção, a partir de um domínio constituído por: (a) marcador de foco (M); (b) foco (F); e (c) resíduo (R). No primeiro membro da construção, $\mathrm{M}$ é constituído de um modificador que indica a dimensão da comparação (mais, menos, tanto/tão); no segundo, a dimensão é omitida e o M é constituído de um elemento comparativo, posto na primeira posição (que/do que, quanto). Na base dessa construção há um elemento comum (R) que garante a possível realização da elipse, ${ }^{8}$ na segunda parte da comparação, como se verifica no esquema abaixo, extraído de Neves (2000, p. 897):

\begin{tabular}{|c|c|c|c|c|c|}
\hline A música é & uma ciência & tanto & quanto & (a música é) & uma arte. \\
\hline $\mathrm{R}$ & $\mathrm{F}$ & $\mathrm{M}$ & $\mathrm{M}$ & $\mathrm{R}$ & $\mathrm{F}$ \\
\hline
\end{tabular}

No que diz respeito ao modo de construção das comparativas, Neves argumenta que essas construções são compostas de uma oração nuclear ou principal $(\mathrm{P})$ e uma oração comparativa $(\mathrm{Q})$, que constitui o segundo termo de comparação, podendo estabelecer-se também em relação mais específica a um de seus constituintes. Dessa forma, o constituinte comparado, em (P), é o primeiro termo da comparação e o constituinte com o qual a comparação é estabelecida, em (Q), é o segundo.

Nesse âmbito, observam-se dois tipos de comparativas: as correlativas e as não-correlativas. Dentre os grupos possíveis de comparativas correlativas, apresentados por Neves (2000, p. 898-900), interessa-nos, especificamente, aquele que abarca enunciados compostos de $\mathrm{P}$, na qual um termo é destacado por uma marca formal como primeiro termo da comparação; ou enunciados com-

7 Isso se dá graças à existência de um elemento comum aos dois segmentos comparados. Nas palavras de Neves (2000, p. 894): “[...] nas construções comparativas, dois membros são comparados a respeito de algo que têm em comum".

8 A elipse, verificada no R, pode ser constatada em extensões variáveis. Neves aponta ainda que, nos casos de comparação, além das elipses de elementos comuns, facilmente recuperáveis a partir da própria estrutura comparativa, há elipses de outros elementos, ou elipses totais, em que a recuperação constitui um processo mais complexo, operado não só em relação ao primeiro membro da comparação, mas também ao contexto, linguístico, situacional ou ainda cognitivo. 
postos de uma oração comparativa que traz, também destacado formalmente, o segundo membro da comparação.

De acordo com Neves, as construções comparativas deste último tipo são sempre de igualdade e implicam uma adição correlativa, do tipo não só... mas também, somada à comparação. Nesse tipo de correlativas, também indicando uma adição correlativa, a autora inclui as comparativas que têm: (a) em P, um elemento de inclusão, como também, assim também, entre outros; e (b) em Q, a conjunção comparativa prototípica como precedida pelo indicador fórico modal assim (assim como):

Assim como o sistema se diferencia (na modernidade) em dois subsistemas (economia e Estado), também ocorrem diferenciaçôes no interior do "mundo vivido"

Por sua vez, as comparativas não-correlativas não apresentam nenhum elemento de P marcado por quantificação relativa, mas têm Q sempre iniciada por conjunção ou locução conjuntiva indicativa de comparação de igualdade:

A neurose, o sintoma, assim como o lapso e o sonho, apenas se tornam inteligiveis dentro da experiência vivida do sujeito [...]

No que tange as relações expressas pelas construções comparativas, mais especificamente as comparativas não-correlativas, sempre relacionadas à expressão de igualdade, Neves aponta que essa igualdade pode ser (i) qualitativa ou (ii) quantitativa:

(i) Isto, porém, só tem graça e faz cócegas se contado por ele mesmo, tal qual está na Arca.

(ii) Tudo isso, tanto quanto a origem e a natureza desses estranhos aparelhos, continua no terreno das hipóteses, das conjecturas.

Em relação a (i), Neves afirma a possibilidade de essa comparação apresentar-se com independencia sintática entre seus membros, sem elipses; e a (ii) a instauração de um efeito de sentido aditivo, com indicação de igualdade de proporção.

\section{Descrição e análise}

\subsection{Aspectos semântico-formais do Padrão B - P assim como Q}

A observação dos aspectos apontados a partir da análise das conjunções/ construçẽes comparativas, realizada por Neves (2000), permite a constatação de uma grande fluidez no que diz respeito aos parâmetros (i) e (ii) que inicial- 
mente são apontados como característicos dessas construções. Basicamente, observa-se a independencia sintática entre os segmentos envolvidos, como nas comparativas não-correlativas, especificamente, as qualitativas. Além disso, a autora chama a atenção para a implicação semântica de adição nas comparativas correlativas de igualdade. A fluidez da caracterização constata-se também em relação à elipse, que pode ou não ocorrer, embora figurando entre as características elencadas pela autora.

Considerando essa descrição e fluidez, de acordo com Neves, a análise específica da construção $P$ assim como $Q$ exige que se parta dos aspectos considerados prototípicos para sua configuração. Assim, consideraremos que, sintaticamente, as aditivas são coordenadas, podendo combinar turnos indefinidamente numa configuração eneária, enquanto as comparativas e as conformativas são interdependentes, como as demais construções adverbiais, podendo, então, fechar dois turnos numa combinação binária.

No domínio da coordenação aditiva, assim como se apresenta de forma mais neutra do que nas construções comparativa e conformativa. Seu papel é acrescer um segundo segmento ao primeiro, recursivamente, independente da direção desses segmentos, determinada pelas variações contextuais (Neves, 2000, p. 739). Dessa forma, a paráfrase por e também é possível e representativa dessa acepção.

Considerando essa caracterização dos aspectos prototípicos das construções comparativas, de um lado, e das aditivas, de outro, e os critérios formais e semânticos elencados para este trabalho, apontamos três acepções para a construção $P$ assim como $Q$, distribuídas nos domínios da comparação e da adição, partindo da descrição de seu comportamento prototípico em direção aos casos em que a fluidez dos aspectos de ambos os domínios torna-se cada vez mais evidente. Além disso, revela-se também uma quarta acepção, fortemente relacionada às anteriores, por meio do traço modal, que lhes é intrínseco, perpassada pela semântica da conformidade. As acepções são:

$P$ assim como $Q$ = construção comparativa não-correlativa

$P$ assim como $Q=$ construção comparativa correlativa

$P$ assim como $Q=$ construção coordenativa aditiva

$P$, assim como $Q /$ assim como $Q, P / P[$ assim como $Q] P=$ construção conformativa 
As principais características de $P$ assim como $Q,{ }^{9}$ construção comparativa não-correlativa são:

(1) tipo de unidade articulada: oração;

(2) sem co-ocorrência de outra conjunção;

(3) posição inicial de Q;

(4) possibilidade de incidência adverbial sobre toda a construção;

(5) possibilidade de apresentação de formas verbais reduzidas;

(6) impossibilidade de inversão da ordem;

(7) relação de dependência entre P e Q;

(8) entrelaçamento: compartilhamento de estruturas diversas; e

(9) relação de sentido: valor comparativo de igualdade.

Essas características traçam o perfil de prototipicidade dessa construção, tal como exemplificamos por meio das ocorrências (1), extraída da TD carta, e (2) das TD caracterizadas pela oralidade: ${ }^{10}$

(1) Meu presado Professor Fidelino | Meus pais muito estimam que o senhor | esteja melhor, assim como esta sua ami- | guinha que sempre o recorda com sal- | dade! Esperamos também que sua espô- sa e os seus estejam passando bem. [FFXX-54f/135]

(2) éh como meu pai é daqui da cidade é médico aqui... éh:: eu resolvi tê(r) ele lá na Santa Casa... que é um hospital que a gente conhece mais... e... o meu irmão mais velho a minha irmã também são médicos... assim como o meu marido...[AC-082/NE438]

Aplicam-se aqui os critérios semântico-formais acima especificados. Vale apenas ilustrar a relação de articulação de orações, seguida pela observação do entrelaçamento formal:

Meus pais muito estimam que o senhor esteja melhor, assim comoesta sua amiguinha muito estima que o senhor esteja melhor.o meu irmão mais velho a minha irmã também são médicos... assim como o meu marido é médico...

Foi constatada também a forma variante $P$ bem assim $Q$.

10 O contexto de realização prototípica dessa construção pode ser constatado também no corpus das TD caracterizadas pela oralidade, como exemplificado, embora a grande maioria dos casos observados nesse tipo de texto aponte aspectos de não prototipicidade. 
A locução juntiva é responsável pela articulação de orações que compartilham a estrutura do Pred, em (1), e do Predicativo, em (2), reservadas as concordâncias com seus respectivos sujeitos ("Meus pais" estimam, em P, "esta sua amiguinha" estima em Q; e "meu irmão mais velho e minha irmã" são médicos, em P, e "O meu marido" é médico em Q). Exatamente por conta da elipse dessas estruturas compartilhadas, que guardam alterações em sua forma, temos um grau de dependência entre P e Q, que impossibilita a inversão da ordem sintática.

A mesma prototipicidade pode ser verificada na ocorrência (3), retirada de um editorial, em que, de acordo com o esquema que segue, Q compartilha com P o sujeito a sua apresentação e o predicativo inoportuna, ambos elípticos em Q. A forma de recuperação pronominal desses elementos compartilhados determina a dependência de $\mathrm{Q}$ em relação a $\mathrm{P}$ e, consequentemente, a impossibilidade de inversão da ordem.

(3) A allegação não passa de um meio pu- $\mid$ ramente administrativo que não póde af- | fectar o direito das assembléas e portan- | to a sua apresentação no parecer da com- $\mid$ missão de justiça nos parece inopportuna, | assim como o foi no relatorio do minis- $\mid$ tro. [APSPXIX-1880/065]

a sua apresentação no parecer da comissão de justiça nos parece inoportuna, assim comoo foi a sua apresentação inoportuna no relatório do ministro.

Embora também prototípicas, as ocorrências (4) e (5), extraídas da TD carta, apresentam características diferenciadas, em relação às anteriores:

(4) Oz Directores actuaes de Imbou, eIta $\mid$ peserica he constante, que Com Zelo, eactividades | seimpregaó nas deligencias uteis, e consernen tes para oaumento, econservassaó das Respecti | vas Aldeas, movendo juntamente aos Indios, quan $=\mid$ do neles reconheSsem tibieza, aque trabalhem, $\mid$ efassaó as suas plantassoens vantajozas; $a \mid$ sim como naó perdem devista oevitarlhes to $\mid$ das asocazioens deque podem sugerir algumas $\mid$ des ordens $[\ldots]$ [AIXVIII-24/63]

Ilustra-se, na sequência, a articulação de orações realizada por assim como e a estrutura compartilhada entre P e Q, a partir dessa ocorrência:

Os diretores atuais de Embu [...], movendo juntamente aos índios, quando neles reconhecessem tibieza, a que trabalhem, e façam as suas plantações vantajosas, assim como 
Os diretores atuais de Embu não perdem de vista evitar-lhes todas as ocasiões de que podem sugerir algumas desordens

Há apenas o compartilhamento do Suj "Os diretores atuais de Embu" entre P e Q, sendo ele elíptico em Q, mas a relação de dependência, constatada na impossibilidade de inversão da ordem dessas orações, é garantida a partir da presença de formas verbais reduzidas de gerúndio e infinitivo (movendo, em P, e evitar-lhes, em Q).

(5) Porque não pescasteis isto $\mid$ ahi com algum moço do $3 .^{\circ}$ anno? Isso | evitaria que viesseis tocar rabeca com ar- $\mid$ co de taquara. $\mid$ Pensasteis então que impunemente se | vai citando estas coisas, assim como se | decora a taboada? || [...] [LRXIX-448/79]

Em (5) observa-se, mais uma vez, apenas o compartilhamento da estrutura de Suj indeterminado pela partícula se:

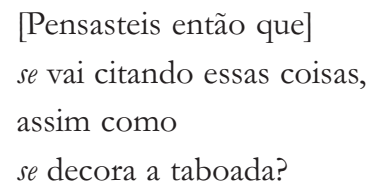

Além da presença de uma forma verbal reduzida no verbo principal da locução "vai citando", característica observada em (4), a especificidade desta ocorrência encontra-se na incidência do advérbio "impunemente" sobre toda a construção $P$ assim como $Q$, o que aponta a relação semântico-formal dos enunciados P e Q. Vejamos:

\footnotetext{
Pensasteis então que impunemente se vai citando estas coisas, assim como impunemente se decora a taboada?
}

Nessa estrutura o advérbio corresponde ao Resíduo, elemento comum entre P e Q, que propicia a sua omissão em Q, já que o próprio mecanismo da construção comparativa responde por ele. A locução juntiva corresponde ao Marcador de foco e as orações comparadas ao próprio Foco, tal como ilustramos no esquema abaixo:

\begin{tabular}{|c|c|c|c|c|}
\hline impunemente & $\begin{array}{c}\text { se vai citando } \\
\text { essas coisas }\end{array}$ & assim como & (impunemente) & se decora a taboada \\
\hline $\mathrm{R}$ & $\mathrm{F}$ & $\mathrm{M}$ & $\mathrm{R}$ & $\mathrm{F}$ \\
\hline
\end{tabular}


Esse tipo de estrutura pode ser encontrado na TD editorial, tal como em (6):

(6) Os seus esforços infelizmente foram sem- | pre perdidos, assim como foram os daquelles | que antes delle, em 1888, e em 18[ininteligivel], na | Actualidade e na Opinião liberal escreveram | no sentido de salvar o partido liberal [...] [APSPXIX-1876/020]

Por sua vez, as principais características de $P$ assim como $Q$, construção comparativa correlativa, observadas a partir da análise descritiva exclusivamente de suas ocorrências na TD carta, já que não foram encontradas ocorrências nos corpora das demais TD, são bastante próximas às já apresentadas em relação à comparativa não-correlativa, revelando diferenças significativas apenas nos itens:

(3) posição inicial/medial de P e posição inicial de Q; e

(9) relação de sentido: valor comparativo de igualdade + valor aditivo.

Esse compartilhamento de características é compreensível, uma vez que, embora esteja em estrutura diferente, ainda encontra-se no domínio da comparação. A ocorrência (7) ilustra um caso prototípico:

(7) A agua do chafariz, assim como | lhe foi arrancada, assim lhe pode, ser restituida. [LRXIX-453/86]

A correlação assim como...assim, articula SVs que compartilham a mesma natureza estrutural e o mesmo Suj:
A água do chafariz
assim como
the pode ser arrancada,
assim
Ihe pode ser restituida

Nessa construção, em presença de formas reduzidas, a primeira parte da correlação (assim como) localiza-se em posição medial de $\mathrm{P}$, e a segunda parte (assim) em posição inicial de Q. A presença dos elementos comparativos 
em P e Q permite a análise da construção como uma comparação correlativa, já que se observa: (a) em $\mathrm{P}$, um segmento textual focalizado por uma marca formal, como o primeiro membro do cotejo; e (b) em Q, outro segmento textual também focalizado por uma marca formal, como o segundo membro do cotejo (de mesma natureza que o primeiro). Implica-se, portanto, uma adição, que se soma à comparação, segundo proposta de Neves (2000):

\begin{tabular}{|c|c|c|c|}
\hline & do mesmo modo que & a água do chafariz & lhe pode ser arrancada \\
\cline { 2 - 4 } & $\begin{array}{c}\text { do mesmo modo } \\
\text { também }\end{array}$ & (a água do chafariz) & lhe pode ser restituída \\
\cline { 2 - 4 } & $\mathrm{M}$ & $\mathrm{R}$ & $\mathrm{F}$ \\
\hline
\end{tabular}

Embora nessa comparação correlativa esteja implícita a noção de adição, constatada na possibilidade de co-ocorrência de também com o segundo elemento da correlação (assim, em Q), ou mesmo, de paráfrase por também, nesse elemento, existe uma restrição, que corrobora nossa análise, quanto à inversão da ordem sintática de $\mathrm{P}$ e Q, graças à relação icônico-temporal implícita na correlação comparativa (a água primeiramente tem que "ser arrancada" para posteriormente, no tempo, "ser restituída").

A ocorrência (8), abaixo, ilustra outra possibilidade de estruturação da locução:

(8) [...] eaSSi por mais que os queira ReduZir ao gremio deSSua igre | ja por velos taõ derramados: ConSsigo poCo fruto aSSim por alguñs | fugirem deSSua aldea; Como outros Sonegados de quem ostem. [AIXVIII-03/41]

Nessa ocorrência, observa-se a correlação assim...como articulando orações que compartilham Suj tal como ilustrado abaixo:

[consigo pouco fruto]

assim

por alguns fugirem de suas aldeias

como

(por) outros serem sonegados de quem os tem

Os termos da correlação comparativa (assim e como) encontram-se em posição inicial de $\mathrm{P}$ e Q, respectivamente, também revelando formas reduzidas. Novamente, a relação de dependência das orações correlacionadas pela locução descontínua é determinada pela estrutura dos enunciados compara- 
dos, já que em P ocorre a redução da conjunção porque, indicativa da causa pela qual o escrevente relata conseguir pouco fruto, elíptica em Q, e, ainda, a relação entre os pronomes usados na indefinição dos Suj compartilhados em correlação anafórica (alguns e outros). Apesar disso, tem-se outro exemplo de adição comparativa, especificamente do tipo "não só...mas também". A ilustração dessa ocorrência no esquema mostra não só a possibilidade de interpretação aditiva, como a relação da locução na marcação dos focos a partir do Resíduo:

\begin{tabular}{|c|c|c|c|c|c|}
\hline $\begin{array}{c}\text { consigo } \\
\text { pouco } \\
\text { fruto }\end{array}$ & $\begin{array}{c}\text { assim } \\
\text { (não só) }\end{array}$ & $\begin{array}{c}\text { por alguns } \\
\text { fugirem de suas } \\
\text { aldeias }\end{array}$ & $\begin{array}{c}\text { como } \\
\text { (mas } \\
\text { também) }\end{array}$ & $\begin{array}{c}\text { (por) } \\
\text { (consigo ponco } \\
\text { fruto) }\end{array}$ & $\begin{array}{c}\text { outros } \\
\text { serem } \\
\text { sonegados }\end{array}$ \\
\hline $\mathrm{R}$ & $\mathrm{M}$ & $\mathrm{F}$ & $\mathrm{M}$ & $(\mathrm{R})$ & $\mathrm{F}$ \\
\hline
\end{tabular}

Por fim, as principais características de $P$ assim como $Q$, construção coordenativa aditiva, observadas a partir da análise descritiva de suas ocorrências nos corpora desta pesquisa, são, como era esperado, mais distantes das já apresentadas em relação às comparativas. Os itens que se distinguem são:

(4) sem incidência adverbial sobre toda a construção;

(5) sem apresentação de formas verbais reduzidas;

(6) possibilidade de inversão da ordem;

(7) relação de independência entre P e Q;

(8) não compartilhamento de estruturas diversas ou compartilhamento pouco incisivo; e

(9) relação de sentido: valor aditivo-inclusivo.

Essas características traçam o perfil prototípico da construção, como exemplificamos por meio de (9), (10) e (11), extraídas das TD carta, editorial e das TD caracterizadas pela oralidade, respectivamente:

(9) [...] | Desejo sin- | cèramente que sua saude se tenha refeito com a volta ao | clima em que o seu corpo foi criado, assim como desejo | que sua distinguida família se encontre bem e que o 1952 | vos seja verdadeiramente favorável. [FFXX-52b/119]

(10) [...] e ninguem | poderá affirmar que a capital argentina | seja mais populosa do que a brasileira, | assim como ninguém poderá chamar, sem grave 
injustiça, de pestillenta a esta | bela cidade de Buenos-Ayres. [OESPXIX1890/151]

(11) Doc.2: uhum ((concordando))... agora:: éh o que é pa/ ENtra aqui (existe) como que a questão é polêmica (né?) aqui entra... éh a questão da liberdade individual... pras pessoas podê(r) legislá(r) sobre seu próprio corpo por exemplo né?... éh assim como:: a obrigatoriedade do uso de seguran::ça... [AC-085/RO530]

Nesse caso, não ocorre nenhum compartilhamento de estruturas entre P e Q, em (10) e ocorre apenas o compartilhamento do Suj elíptico em P e Q, em (9), e do Pred, em (11):

$\varnothing$ Desejo sinceramente que sua saúde se tenha refeito com a volta ao clima em que o seu corpo foi criado,

assim como

$\varnothing$ desejo que sua distinguida família se encontre bem

aqui entra... éb

a questão da liberdade individual... pras pessoas podê(r) legislá(r) sobre seu próprio corpo por exemplo né?...

éh assim como::

aqui entra... éh

a obrigatoriedade do uso de seguran::ça...

Há, diferentemente do que observamos nas demais ocorrências apresentadas, a possibilidade de inversão da ordem sintática sem que seja provocado qualquer prejuízo formal ou semântico, o que evidencia uma independência de $\mathrm{Q}$ em relação a $\mathrm{P}$ :

(9’) Desejo que sua distinguida família se encontre bem assim como desejo sinceramente que sua saúde se tenha refeito com a volta ao clima em que o seu corpo foi criado [...]

(10') [...] e ninguém poderá chamar, sem grave injutiça, de pestillenta a esta bela cidade de Buenos-Ayres assim como ninguem poderá affirmar que a capital argentina seja mais populosa do que a brasileira. 
(11') [...] aqui entra... éh a obrigatoriedade do uso de seguran:: ça éb assim como:: a questão da liberdade individual... pras pessoas podê(r) legislá(r) sobre seu próprio corpo por exemplo né?...

Diante desses fatores, constata-se que, nessas ocorrências, o papel da locução conjuntiva assim como é coordenar as estruturas de natureza completiva de P e Q no interior da mesma proposição, sendo parafraseável por e também. Trata-se, portanto, de um valor aditivo que expressa inclusão, responsável por assinalar que a informação veiculada pelos constituintes, sob seu escopo, em $\mathrm{Q}$, deve ser acrescentada à informação expressa, em $\mathrm{P}$, como subparte de uma estrutura cumulativa mais ampla.

Nessa função de coordenação aditiva, a integração entre P e Q é menor do que na de comparação, já que se trata de orações independentes. Em outras ocorrências desse tipo, verifica-se um compartilhamento maior de estruturas de P em Q (i. é, para além do SN Suj), no entanto, em nenhum dos casos, há alteração de quaisquer aspectos (como, por exemplo, flexões verbais) dos termos elípticos em Q, como observamos nos casos de comparação, o que demonstra ser esse entrelaçamento menos incisivo do que aquele. As ocorrências (12) e (13), representativas das TD carta e editorial, ilustram casos em que há esse tipo de compartilhamento, chamado aqui de menos incisivo:

(12) [...] ella lhe pede que logo que tenhas occa | sião lhe mande um retrato da tua noiva que | deseja conhecer assim como dos teus Irmãos, | tua e de Lafaiete ja tenho. [CPXIX-23/28]

(13) A attitude do famoso opposicionista de $\mid$ tantos ministerios e a pressa com que | procede arregimentando a camara para | apoiar sem o maior exame o programma | do gabinete de 28 de março nos conven- | cem de que os chefes liberaes mesmos es- | tão duvidosos do exito da missão do sr. | Saraiva, assim como estamos nós. [APSPXIX-1880/067]

Ilustra-se, na sequência, a articulação de orações aí realizada por assim como:

que lhe mande um retrato da tua noiva

assim como

que the mande um retrato dos teus irmãos 
os chefes liberaes mesmos estão duvidosos do êxito da missão do sr. Saraiva, assim como

nós estamos duvidosos do êxito da missão do sr. Saraiva.

Em (12), P e Q compartilham toda a oração completiva com exceção dos respectivos SPrep Mod. (da tua noiva, em P, e dos teus irmãos em Q). Já em (13), há o compartilhamento do predicativo e de seu complemento. Não há, como se constata, alteração formal em relação às porções compartilhadas de P em Q, elípticas em Q, o que possibilita a inversão da ordem sintática, já constatada na ocorrência anterior:

que lhe mande um retrato dos teus irmãos assim como da tua noiva.nós estamos duvidosos do êxito da missão do sr. Saraiva assim como estão os chefes liberais mesmos.

Sendo assim, o papel de assim como é o de explicitar a coordenação das estruturas de mesma natureza Modificadora e Predicativa de P e Q, expressando valor aditivo-inclusivo, novamente podendo ser parafraseado por e também.

(12') que the mande um retrato da tua noiva assim como (e também) dos teus irmãos.

(13’) os chefes liberais mesmos estão duvidosos do êxito da missão do sr. Saraiva, assim como (e também) nós estamos.

Em todas as ocorrências analisadas até o momento, observou-se, por um lado, a independência sintático-semântica das orações articuladas pela coordenação, estabelecida pela locução juntiva, e, por outro, a dependência, nesses mesmos domínios, das orações articuladas pela locução juntiva com valor comparativo (não)correlativo, de forma a ilustrar casos prototípicos desses funcionamentos. Passamos, agora, a focalizar os casos que, de alguma forma, se afastam do centro prototípico, podendo demonstrar: (i) contextos importantes para o desenvolvimento dessas relações sintáticas e, principalmente, semânticas de assim como; e (ii) a relação de fluidez existente entre esses dois grandes grupos: a comparação (não)correlativa e a coordenação, a partir, principalmente, do aspecto semântico da adição, como observado na proposta de Neves.

As ambiguidades constatadas em relação a (i) e (ii) associam-se às características expressas em (2), (4), (8) e (9), que dizem respeito, respectivamente, à co-ocorrência de outra conjunção, à incidência adverbial, ao 
entrelaçamento de estruturas e às relações de sentido expressas nas construções. De modo geral, a ambiguidade relacionada à (9) sempre se envolve nas observadas em (2), (4) e (8).

A ocorrência (14), extraída do corpus da TD carta, ilustra um caso de ambiguidade contextual relacionado à presença de um advérbio e, especificamente, ao surgimento, via GR, do traço comparativo de assim como:

(14) Rogamos aquelles dos nossos assignantes do interior que nos estão a dever suas assignaturas o obzequio de mandar satisfazel-as; assim como igualmente rogamos áquelles que estão com suas assignaturas findas, ou quasi a findar hajão de mandar renoval-as para não haver demora na remessa. [LRXIX-4998/101]

Verifica-se que assim como encontra-se sem a co-ocorrência de outra conjunção e de formas reduzidas, em início de Q, articulando orações independentes, que compartilham apenas o Suj. elíptico "nós", tornando possível a inversão sintática. Trata-se de mais um caso de coordenação aditivo-inclusiva, parafraseável por e também.

Destaca-se o fato de que, nesse contexto, há a incidência do advérbio comparativo "igualmente", que estabelece a comparação não-correlativa entre $\mathrm{P}$ e Q, sendo Q coordenado por assim como. Temos, portanto, um ambiente propício para o empreendimento de uma mudança de significado via transferência metonímica, facilitada pelas congruências existentes entre adição e comparação: as comparações realizadas pela locução são sempre de igualdade e as adições se dão sempre entre iguais (Neves, 2000), propiciando uma relação de redundância entre adição e comparação, reforçada, ainda, pela própria estrutura sintagmática dos enunciados, já que nas construções comparativas e nas coordenadas, o Suj, comum a P e Q, sempre precede os dois predicados, ficando elíptico, na maior parte das vezes. A distinção semântico-formal entre ambas torna-se sutil e observável apenas nas relações de (não)dependência, sabendo-se que, conforme a análise apresentada até o momento, sintaticamente, as aditivas são coordenadas, enquanto as comparativas são interdependentes, proximamente a outras construções adverbiais. Isso porque, nas comparativas, verificam-se dois enunciados que se fecham em si, formando o que Neves (2000) chama de combinação binária, e de ordenação, em princípio, irreversível. Diferentemente, na coordenação aditiva, combinam-se enunciados indefinidamente, o que fundamenta o conceito de inclusão, usado aqui. 
Toda essa proximidade categorial está refletida na ocorrência (14), em que pode ser presumida uma relação, senão cronológica, ao menos, gramatical, entre a coordenação aditiva, realizada por assim como, e a comparação, nesse caso, realizada por igualmente, permitindo uma transferência de significado comparativo do advérbio para a locução via pressão contextual.

A ocorrência (15), também extraída da TD carta, ilustra a ambiguidade contextual relacionada à co-ocorrência de outra conjunção e, especificamente, ao surgimento, via GR, do traço, agora aditivo, de assim como:

(15) Cumprimentamos-o com um abraço, faço | Votos pelo seu [ininteligível], e bem assim o de sua Excelentíssima Familia, para quem peço os meus | respeitos. [FFXX-25b/113]

Primeiramente, constata-se uma variante de assim como, em contexto da conjunção $e$, o que acarreta sua posição não-inicial em Q. Aqui ocorre a articulação de orações pela conjunção $e$, que assume a função coordenativa, demarcando o valor de adição-inclusão. ${ }^{11}$ Nessa articulação, há o compartilhamento do Suj elíptico em P e de grande parte do Pred:

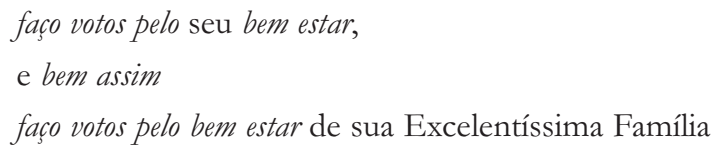

Em Q, "bem estar" é substituído por 0 , e o pronome que modifica "bem estar", em P, "seu”, é substituído pelo SPrep "de sua Excelentíssima Família". Embora em construção mais complexa do que as até aqui analisadas (também por conta das condições da transcrição), é nítida a impossibilidade de inversão da ordem sintática, uma vez que a construção não conta apenas com compartilhamento de estruturas entre $\mathrm{P} \mathrm{e} \mathrm{Q}$, mas também com o emprego de itens que estabelecem relações de referência anafórica. Constata-se, assim, uma dependência entre P e Q e, consequentemente, uma relação de comparação, codificada pela locução bem assim. Estamos, portanto, diante de um contexto oposto àquele analisado anteriormente, i. é, a coordenação é, agora, estabelecida pela conjunção $e$ e a comparação, pela locução bem assim.

11 Interpretamos o trecho ininteligível da transcrição, de acordo com o contexto, como "bem estar". 
Dessa forma, a transferência de significado por pressão contextual, parte da noção de adição-inclusão, para a de comparação, já presente em bem assim, o que acaba comprovando, mais uma vez, a redundância entre os aspectos semânticos que perpassam essas duas noções. ${ }^{12}$

Por sua vez, a ocorrência (16) representa as construções cuja ambiguidade é determinada pela colocação pronominal, ou seja, pelo entrelaçamento de estruturas:

(16) Confiante na sua promessa, aqui | fica á espera de voltar a vel-o em | maio, assim como D. Dulce e a He- | lena, a de valor muito sincera- | mente amiga, [FFXX-41b/132]

Em (16), assim como se apresenta, no início de Q, sem co-ocorrência de outra conjunção e incidência adverbial. Há compartilhamento, em Q, do Suj e núcleo do Pred:

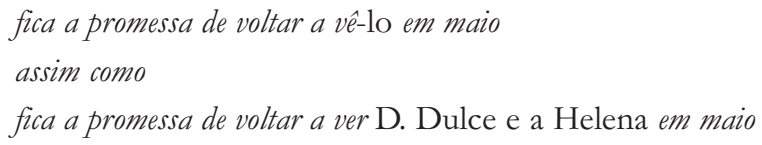

Embora seja possível a paráfrase da locução conjuntiva por e também, corroborando a leitura da construção coordenada aditivo-inclusiva, o emprego do pronome oblíquo provoca uma alteração na forma verbal apresentada em P em relação à em Q, e, consequentemente, a inversão torna-se impossível sem que incidam alterações na construção original, o que constitui um traço característico da relativa dependência formal de Q em relação a P, como se identifica nas comparativas não-correlativas:

* fica a promessa de voltar a ver D. Dulce e a Helena em maio assim como (e também) lo.

12 Esse tipo de contexto de co-ocorrência da construção comparativa não-correlativa com a conjunção coordenativa $e$ é recorrente também em dados de fala, como exemplifica-se em: [...] ele teve que pará(r) de pescá(r) por causa dal do passarinho [Doc.: do pássaro] toda vez assim eu falo - "ai pai você contan(d)o essas histórias num dá nem pra acredí [tá(r)"] - 6[Doc.: é]... e minha mãe conta que foi verdade que aconteceu mesmo... e assim como essa tem muitas ou::tras... [AC-086/ NR552], em que há uma relação de dependência entre P e Q determinada pelo uso do demonstrativo essa, impossibilitando a inversão da ordem sintática, numa relação claramente comparativa. 
Além disso, a presença da forma reduzida em $\mathrm{P}$ ajuda a caracterizar o traço de dependência. Assim, também a leitura comparativa é possível. Ilustramos ambas as possibilidades no esquema abaixo:

\begin{tabular}{|c|c|c|c|c|}
\hline $\begin{array}{c}\text { fica a } \\
\text { promessa de } \\
\text { voltar a ver }\end{array}$ & você (-lo) & $\begin{array}{c}\text { assim como } \\
\text { (e também) }\end{array}$ & $\begin{array}{c}\text { (fica a promessa } \\
\text { de voltar a ver) }\end{array}$ & D. Dulce e Helena \\
\hline $\mathrm{R}$ & $\mathrm{F}$ & $\mathrm{M}$ & $\mathrm{R}$ & $\mathrm{F}$ \\
\hline
\end{tabular}

O quadro mostra, na estrutura de marcação de foco nas comparativas, que ambas as leituras são possíveis, constituindo um exemplo de ambiguidade semântico-formal da locução assim como em relação à coordenação aditivoinclusiva e à comparação não-correlativa. Esse tipo de ambiguidade é constatado também no corpus da TD editorial:

(17) [...] por- | que não podemos attribuir á ignorância os $\mid$ seguintes periodos do seu editorial do dia $\mid 1^{\circ}$ do corrente: ||$<<$ A Provincia de São Paulo, orgão de um | grupo achismado, nega-lhes (aos liberaes) | assim como aos conservadores, capacidade | moral; julga impossivel encontrar com a | propria lanterna de Diogenes um homem | approveitavel entre as fileiras dos partidos mi- | litantes. [...]>> [APSPXIX-1875/008]

Nesse tópico, temos o compartilhamento do sujeito e do núcleo do Pred. Com a informação entre parênteses, correspondente ao referente do oblíquo em P, é reduzida a dependência de P e Q, tornando a inversão da ordem possível. Assim, podemos fazer a leitura do trecho também com a paráfrase por $e$ também.

Um caso específico de ambiguidade provocada pelo entrelaçamento de estruturas, envolvendo indiretamente a colocação pronominal observa-se em (18):

(18) Agora aqui estou e como dizia velha canção carnavalesca: daqui não saio, daqui ninguém me tira. Dinorah vai bem de saúde assim também o marido.[...] [FFXX-55d/116]

O primeiro aspecto que chama a atenção, em (18), é a ocorrência de uma variante de assim como, que apresenta a mesma posição inicial em Q, sem co-ocorrência de outra conjunção, incidência adverbial ou formas reduzidas e 
a funcionalidade de articular as orações P e Q. Há o compartilhamento do Pred:

Dinorah vai bem de saúde

assim também

o (seu) marido vai bem de saúde

Embora não haja alteração nas estruturas compartilhadas entre P e Q, a presença de um pronome inferível/implícito em Q, responsável pela identificação de que se trata do "marido de Dinorah", torna agramatical a inversão da ordem sintática:

*o (seu) marido vai bem de saúde assim também Dinorah

A agramaticalidade é acarretada pela perda da relação semântica entre os SN "Dinorah" e "o marido", tão clara originalmente que até dispensa o possessivo. Isso mostra que há uma dependência entre $\mathrm{P}$ e Q capaz de tornar rígida a ordenação e caracterizar a construção como comparativa nãocorrelativa. Mais uma vez, o esquema ilustra a marcação da focalização na estrutura e ajuda a comprovar sua qualidade:

\begin{tabular}{|c|c|c|c|c|}
\hline Dinorah & $\begin{array}{c}\text { vai bem de } \\
\text { saúde }\end{array}$ & $\begin{array}{c}\text { assim } \\
\text { também }\end{array}$ & o (seu) marido & (vai bem de saúde) \\
\hline $\mathrm{F}$ & $\mathrm{R}$ & $\mathrm{M}$ & $\mathrm{F}$ & $\mathrm{R}$ \\
\hline
\end{tabular}

Entretanto, a presença do item "também", na formação da locução, propicia a leitura como uma adição inclusiva, como e também, constituindo, novamente, a ambiguidade entre a coordenação aditivo-inclusiva e a comparação não-correlativa. O mesmo observa-se nas ocorrências (19), extraída da TD editorial, e (20), extraída das TD caracterizadas pela oralidade, em que a contiguidade entre assim como e também ilustra a fluidez entre essa acepção e a comparativa.

(19) Tudo isso explica-se; muita cousa descul- | pa-se e tolera-se, até certo ponto: mas ainda | assim é preciso que a população estranha á | festa tenha certeza de que anda resguardada | pela vigilancia policial, assim como também | é preciso que os barulhentos e mal inten- | cionados persuadam-se de que arriscam-se a | encontrar a mão repressora das auctoridades [...]. [APSPXIX-1876/018] 
(20) e:: foi o que o:: técnico Bernardinho fez agora que ele tá trabalhan(d)o com esses jogadores há:: muito tempo assim... alguns são bem velhos já de carre(i)ra... alguns são mais novos... é até legal ele mesclá(r) assim porque... a experiência dos mais velhos vai sê(r) passada com certeza pros mais NOvos... e assim por diante né?... assim como tam(b)ém os mais velhos tem muito a aprendê(r) com quem é mais novo [...] [AC-054/RO364]

Nessas duas ocorrências, a relação de independência entre P e Q, confirmada a partir do não compartilhamento estrutural e da possibilidade de inversão da ordem sintática, somada à co-ocorrência contígua de também, levanos a analisá-las como casos que, apesar de ilustrarem a fluidez entre comparação e coordenação, determinada pelas características contextuais, ainda assim, devem ser classificados como mais próximos da segunda.

Exclusivamente nos dados das TD caracterizadas pela oralidade, observa-se uma especificidade relacionada à emergência de usos comparativos não-correlativos de assim como. Vejamos (21):

(21) Inf.: eu vô(u) contá(r) do meu namoro como que começô(u).... ((barulho ao fundo de carro passando)) conhe-ci... éh:: essa pessoa:.... ele mora aqui faz mais ou menos uns quinze anos... mudô::(u) do lado da minha casa... mudô(u) lá::... era amiga dele::... desde peque::na conversa::va brinca::va... tudo... e::... NIsso nós fomos assim sentindo o::/ assim era criANça mas a gente sempre era... bem apega::do a:: a famí::lia meu pai minha mãe... e morô(u) uns cinco anos naquela casa... depois muda::ram foram morá(r)... um pouco longe de casa... éh:.... não tive mais contato assim como era antes... mas sempre conversei com ele... tinha amiza::de tal... [AC-052/NE149]

Numa primeira análise, essa ocorrência parece de fato caracterizar mais um uso da locução juntiva relacionado à comparação não-correlativa, uma vez que há a articulação de P e Q, sendo que Q compartilha o OD “contato”, de $\mathrm{P}$, que assume aí a função de Suj, impossibilitando a inversão da ordem sintática, juntamente com a relação temporal icônica estabelecida entre essas orações. Entretanto, a análise prosódica dessa ocorrência, a partir da audição do inquérito, revela o seguinte contexto sintático:

Não tive mais contato assim: como era antes... 
Essa interpretação prosódica revela a existência de uma pausa acústica percebida claramente entre o segmento encerrado por assim e o introduzido por como, sendo também realizada uma curva entoacional ascendente em assim (marcando o final desse enunciado fonológico). A partir desses dados, podemos constatar que o item assume uma sinalização, ao mesmo tempo anafórica, sinalizando todo o ST anterior, no qual é descrito o tipo de contato mantido entre o falante e a pessoa em questão, e catafórica, sinalizando a comparação introduzida pelo operador de comparação como. Esse contexto, mais característico de dados das TD caracterizadas pela oralidade, também pode ser observado em um contexto de escrita, especificamente na ocorrência (22), extraída da TD editorial, em que, no lugar da possível pausa, evidencia-se o emprego de vírgula:

(22) Depois de ter sido desmoralisada a nova / lei eleitoral, continuaremos a servirmo-nos | della ou nos darão a eleição directa, a idéa | dominante no esclarecido espirito de um dos | chefes da situação, o sr. Paulono de Souza? | Assim, como estas, muitas outras questões | Interessantes e de actualidade ficarão pairan-|do na dúvida.[APSPXIX-1876/0250]

Esse contexto parece ter importância bastante relevante para a interpretação do caminho de mudança que leva à construção comparativa nãocorrelativa, evidenciando um estágio anterior a essa construção, em que assim e como ainda não estão reanalisados na locução comparativa.

Outro contexto específico pode ser observado nas ocorrências (23) e

(23) Inf.: na época foi um susto porque:: eu num sabia falá(r) praticamente nada e o po(u)quinho que você sabe falá::(r) assim que nem... pai... mãe:: vô vó o po(u)quinho que você sabe você esquece a hora que você chega lá [...] [AC-084/NE495]

(24) Inf.: às vezes tem algum pezinho de coisa assim que nem o meu genro plantô(u) um pé de pitanga lá ago::ra... e do o(u)tro lado tem um pezinho de goiaba... mas é po(u)ca coisa [...] [AC-152/DE1240]

De forma inédita, os dados das TD caracterizadas pela oralidade revelam ocorrências, como as acima, em que assim aparece seguido por que nem, uma construção típica da fala, que pode, entre outras, assumir função compa- 
rativa. Também aqui, a análise prosódica revela pausa após o segmento encerrado por assim e o introduzido por que nem, e o mesmo contorno entoacional ascendente em assim, o que evidencia, mais uma vez, um contexto não reanalisado de assim que nem em locução comparativa, em que assim é responsável por uma sinalização catafórica que aponta a inserção de um exemplo introduzido por que nem. Em (23) a repetição do segmento "o pouquinho que você sabe", realizado antes e depois do ST "pai... mãe:: vô vo", ajuda a confirmar, estruturalmente, a natureza exemplificativa desse ST introduzido por que nem e sinalizado por assim. Em (24), não se constata uma repetição de estruturas, mas uma pausa que limita o final do ST exemplificativo "o meu genro plantô $(u)$ um pé de pitanga lá ago::ra... e do o(u)tro lado tem um pezinho de goiaba..." e a continuação do desenvolvimento tópico.

Apesar de não estarmos diante de um caso reanalisado, como já foi apontando, esse contexto, além de representar, assim como o anterior, passo importante no processo de GR da locução, ainda evidencia uma variação em sua forma, que lança mão de uma construção bastante informal (que nem).

Diante dos casos prototípicos e das especificidades dos ambíguos de ambas as acepções da construção $P$ assim como $Q$, sugerimos o seguinte contínuo:

coordenativas aditivas (eneárias) > comparativas não-correlativas (aditivas/binárias) $>$ comparativas correlativas (binárias)

Podemos dizer que as comparativas não-correlativas mantêm as características da interdependência e do binarismo, como afirma Neves (2000, p. 742), mas podem somar a essas características o valor semântico aditivo da coordenação, representando um ponto médio do contínuo, análogo à ambiguidade entre as duas acepções. Por outro lado, as coordenadas aditivas prototípicas são independentes e eneárias, e as comparativas correlativas são dependentes e binárias. $\mathrm{O}$ valor aditivo pode ser depreendido em todas elas, embora em graus diferenciados; mais claramente nas coordenadas e mais opacamente nas comparativas correlativas, graças à existência, entre a comparação e a adição, de uma relação redundante, já que toda construção comparativa é uma reunião entre iguais, no caso da comparação de igualdade aqui focalizada, enquanto toda construção aditiva também se faz entre iguais.

Ainda em relação ao Padrão (B), faremos algumas considerações a partir do estudo de Haspelmath e Buchholz (1998) que focaliza construções que expressam igualdade e similaridade nas línguas européias. Esses domínios incluem 
construções de: igualdade, como (a), similaridade, como (b) e também "role phrases", como (c):

(a) Robert is as tall as Mary.

(b) Robert sings like a nightingale.

(c) He works as an engineer. ${ }^{13}$

Os autores utilizam a seguinte terminologia para falar das características estruturais dessas construções:

\begin{tabular}{|c|c|c|c|c|}
\hline Robert is & as & tall & as & Mary. \\
\hline $\begin{array}{l}\text { Comparee } \\
\text { (COM) }\end{array}$ & $\begin{array}{l}\text { Parameter } \\
\text { marker } \\
\text { (PAM) }\end{array}$ & $\begin{array}{l}\text { Parameter } \\
\text { (PARA) }\end{array}$ & $\begin{array}{c}\text { Standard marker } \\
\text { (STM) }\end{array}$ & $\begin{array}{l}\text { Standard } \\
\text { (STAN) }\end{array}$ \\
\hline
\end{tabular}

Haspelmath e Buchholz (1998) identificam algumas características tipicamente européias das construções acima que provêm fortes evidências para a existência de uma "European Sprachbund", chamada de "Standard Average European (SAE)". Assim, no núcleo da SAE, construções de igualdade e de similaridade são codificadas de modos não atestados nas línguas não-SAE da Europa. As características importantes das SAE codificadas nesses domínios são:

(i) construçẽes de igualdade tendem a mostrar uma marcação dupla, i. é, o SN STAN e o predicado na construção são marcados por um item analítico. Exemplos disso são as...as, em Inglês, aussi...que, em Francês, tam...quam, em Latim e tão...como, em Português. Nos casos típicos, os dois marcadores são relacionados, sendo o marcador no predicado uma forma demonstrativa e o no SN STAN uma relativa/interrogativa. Esse tipo de construção não é encontrado em grande parte das línguas para além da SAE, onde somente uma marcação, ou no predicado ou no SN STAN, aparece como regra.

(ii) construções de similaridade tendem a marcar somente o $\mathrm{SN}^{14} \mathrm{STAN}$, usando, para isso, o mesmo marcador empregado no SN STAN das construções de

13 Neste trabalho, não trataremos de (c), uma vez que essa construção permite apenas paráfrase por como, em português.

14 Outras configurações sintáticas também são previstas neste lugar. 
igualdade. Apesar de o Francês (comme [similaridade] vs que [igualdade]) e o Inglês (as vs likee) serem exceções notáveis para essa tendência, a grande maioria das línguas SAE, como mostram os autores, confirmam-na.

Além disso, Haspelmath e Buchholz (1998) enfatizam que enquanto uma construção de igualdade relaciona-se à igualdade de extensão, uma construção de similaridade relaciona-se à igualdade de modo.

A partir dessas características, tanto em relação às tendências de distribuição dos marcadores (PAM e STM), quanto à distinção entre as noções de extensão e modo, relativas, respectivamente, à igualdade e similaridade, podemos, num primeiro momento, relacionar os usos do Padrão (B), especificamente, as construções comparativa não-correlativa, comparativa correlativa e também a coordenativa aditiva às construções de similaridade, uma vez que, em todas elas, depreende-se uma relação de igualdade de modo, estreitamente ligada ao próprio item assim.

Apesar dessa constatação genérica, algumas especificidades devem ser levantadas. Primeiramente, Haspelmath e Buchholz (1998) afirmam que, em muitas línguas, não há um PAM em construções de igualdade, devido ao fato de que essas construções podem ser divididas em dois subtipos: (i) o das construções canônicas, que apresentam o PAM e o STM, como se exemplifica com "Minha irmã é tão bonita como você", em que está clara a relação de extensão; e (ii) o das construções com apenas um STM, como o caso do exemplo em italiano oferecido pelos autores: "Mia sorella è carina come te", em que também se depreende a noção de extensão. É fato que, no português, a construção "Minha irmã é bonita assim como você" também é capaz de representar a contento essa noção de extensão, caracterizando, portanto, um uso possível dessa locução em construção de igualdade, ainda que não-canônica. Vale lembrar, no entanto, que em nossos corpora tal uso não foi atestado.

Para apresentarmos a segunda especificidade, relacionada pontualmente à construção comparativa correlativa, retomaremos o caso dos PAM e STM do Francês, também oferecido por Haspelmath e Buchholz (1998). Os autores recorrem a informações diacrônicas para justificar a participação da locução aussi...que, do Francês, nos casos de construções de igualdade. A primeira semelhança com a nossa construção assim...como está na própria formação, já que, em Francês, aussi deriva do Latino demonstrativo de modo sic (thus, so) reforçado por au-, exatamente como ocorre com assim, em Português. No Francês antigo, construções de igualdade apresentavam-se com o STM comme 
(aussi grande comme not), mas este foi perdendo lugar para que. Assim, pelo menos diacronicamente, enxergarmos uma relação muito forte com a construção comparativa correlativa do Português (Padrão (B)), que se mantém com como nos nossos dados. Podemos sugerir, então, que, apesar da relação mais transparente com construções de similaridade, a partir de usos marcados pela noção de modo, é possível identificarmos relações mais opacas com outras construções caracterizadas como de igualdade, por meio da grande similaridade formal evidenciada em percursos de desenvolvimento como o do Francês.

Antes de concluirmos essas últimas considerações, devemos colocar que, na mesma direção em que aponta esta análise, Haspelmath e Buchholz (1998) fazem a seguinte colocação, em nota de rodapé: "O standard marker relaciona-se também a 'modo' na Georgia (rogorc < ra gvar(a)-c(a) 'what kind'). Também nas línguas eslavas o sentido original de tak/jak (kak) é modo, e no Francês (aus)si do Latim sic ('in this way'). Parece haver uma tendência geral para as expressões de modo ('in the way') desenvolverem-se para expressões de grau ('to what extent')" (p. 331, tradução nossa). ${ }^{15}$ Dessa forma, sugerimos, a partir desse paralelo com outras línguas européias, que embora os usos das construções de P assim como Q estejam mais explicitamente relacionados à similaridade (igualdade de modo), há indícios relevantes que apontam o movimento de mudança que os relaciona a construções de igualdade de extensão, confirmando, portanto, a tendência sugerida pelos autores, no caso desse Padrão do Português.

Apresentemos, por fim, a acepção conformativa de assim como, a partir, primeiramente, de uma ocorrência extraída da TD carta:

(25) No artigo - Insomnia - que hoje publicamos vem uma censura á Camara Municipal por não ter dado aos providenciais precisas para o dessecamento do tanque do Zunega, visto que pelo Excelentíssimo Governo da Provincia ja lhe forão presentes os planos e orçamentos d'aquela obra, assim como necessaria para a mesma obra. | |[LRXIX-495/99]

Nessa ocorrência, a locução inicia Q, sem co-ocorrência de outra conjunção, incidência adverbial e formas reduzidas, de acordo com a maioria dos

\footnotetext{
"The standard marker is also on a work 'manner' in Georgian (rogorc < ra gvar(a)-c(a) 'what kind'). Also in the Slavic languages the original sense of tak/jak (kak) is manner, and Franch (aus)si is from Latin sic ('in this way'). There seems to be a general tendency for manner expressions ('in the way') to develop into degree expressions ("to what extent')."
} 
casos já analisados. Diferentemente, aqui, existe, ao invés de uma relação aditiva ou comparativa, uma relação de conformidade desempenhada pela locução. Entretanto, na determinação do parentesco entre conformidade e comparação, está o traço modo, materializado em ambas no item assim:

[visto que pelo Excelentíssimo Governo da Provincia] já lhe foram presentes os planos e orçamentos d'aquela obra, assim como (conforme) necessário para a mesma obra.

A relação de conformidade apresenta-se sobre o formato $P$, conforme $Q$, no qual há o compartilhamento entre a estrutura "d'aquela obra", em P, e a retomada, em Q, pela referência "a mesma obra". Nessa ocorrência, a relação sintática entre os constituintes também é de dependência, como nas comparativas, mas, diferentemente do que se observa naquelas, constata-se a possibilidade de inversão da ordem sintática.

Embora na TD carta esse uso seja restrito, uma vez que encontramos apenas uma ocorrência, na TD editorial ele parece mais comum. Vejamos os exemplos abaixo:

(26) Parece-nos mais prudente e de melhor con- $\mid$ selho não exigir o regulamento a frequencia | obrigatória dessas aulas nem mesmo para os | filhos dos catholicos. || É esta a conclusão logica do principio que | s. exc. admittiu. || A reforma assim como vae ser executada | permitte um resultado contrario ao pensa- mento do s. exc.[...]. [APSPXIX-1878/044]

(27) A cidade de S. Paulo póde ser victima de / uma peste que dizime parte de sua população. || É preciso tomar-se qualquer providencia a | respeito. || As cousas assim como vão constituem uma | ameaça muito séria á vida dos habitantes da | cidade. [APSPXIX-1882/086]

(28) Deu-lhes principio um presidente, senador | do imperio, com certa autoridade propria e in- fluencia definida. D'ahi para ca ficaram as | obras sem execução. || Peçam ao menos aos srs. representa4ntes da | provincia que o producto d'aquellas vendas | seja applicado a taes obras, offerecendo para | isso uma emenda ao orçamento. || O que é preciso comprehenderem é que os edi- | ficios, assim como se acham, vão se estragan| do de dia em dia, ao passo que as despezas | avultam com os concertos e alugueis de pre- | dios particulares. [APSPXIX-1883/091] 
Nota-se o compartilhamento do Suj. de P e Q, (cf. as reescritas abaixo), sendo essa estrutura deslocada para a posição temática de P e elíptica em Q. Apesar disso, a inversão sintática de P e Q é possível, sem prejuízo para a acepção conformativa:

(26') Conforme a reforma vai ser executada, (P)

a reforma permite um resultado contrário ao pensamento de s. exc. [...] (Q)

(27’) Conforme as coisas vão, (P)

as coisas constituem uma ameaça muito séria à vida dos habitantes da cidade.(Q)

(28') Conforme os edificios se acham, (P) os edificios vão se estragando de dia em dia [...] (Q)

Nos editoriais, encontra-se também Assim como Q, P, como (29), em que, sem compartilhamento estrutural entre $\mathrm{P}$ e Q, é possível a inversão sintática:

(29) Assim como vão as cousas no to- | cante á instrucção publica, dentro de | pouco tempo só haverá uma provi- | dencia util a tomar : reduzir a verba | para a despeza com o ensino pri- | mario. [APSPXIX-1889/138]

Em dados das TD caracterizadas pela oralidade, foi constatada apenas uma ocorrência conformativa da locução assim como, em contexto sem compartilhamento estrutural, como o exemplificado em (30). Vejamos:

(30) Doc.: que que ela... por que que ela ela é contra tão contra assim o namoro? Inf.: porque ela num::... ela:: assim sente muito ciúmes ela acha que eu sou muito NO::va que eu tenho que aproveitá(r) a vi::da que eu tenho que estudá::(r) que... que num vale a PEna... que... e ela é assim como eu disse ela... pra ela só a família dela presta e tem que namorá(r) primo com primo irmão com irmão e num dá certo... [AC-052/NE171]

Nessa ocorrência, a oração conformativa iniciada por assim como ocorre após o início de $\mathrm{P}$ "ela ê", truncado para a inserção de Q, e retomado na 
sequência, seguido por correção "ela... pra ela só a família presta [...]”. Dessa forma, constata-se que, da mesma forma como se depreenderam as estruturas $P$, assim como $Q$ e Assim como $Q, P$, é possível também a intercalação de $Q$, em P, em P [assim como Q]P, como confirma a ocorrência em (30).

Essa acepção mostra que o traço modal, carregado por assim, representa o elo existente entre as acepções conformativa, comparativa e aditiva da mesma locução. Embora a dependência sintática tenha sido constatada em relação às comparativas, ela encontra-se intrinsecamente associada ao entrelaçamento de estruturas entre $\mathrm{P}$ e Q, constatado na construção. Em relação à acepção conformativa, a dependência entre as orações não se correlaciona a esse traço, havendo possibilidade de inversão da ordem. Essas considerações têm unicamente o objetivo de chamar a atenção para um posicionamento diferenciado dessa acepção da locução, localizada mais à direita no continuum PARATAXE vs HIPOTAXE, em relação às demais, representando mais um forte indício da fluidez que existe entre elas.

\subsection{Discussão analítica: as relações e interdependências do Padrão B - assim como}

Como foi afirmado anteriormente, os padrões, tais como o descrito acima, em que o item assim se envolve com relações interproposicionais, justificam uma discussão acerca das relações lógico-semânticas e da interdependência existente entre as porções componentes da oração complexa, a partir dos pressupostos teóricos apresentados em 3.

À notação 1 (inicial) e 2 (continuação), na parataxe, e $\alpha$ (dominante) e $\beta$ (dependente), na hipotaxe, acrescentar-se-ão $\mathrm{P}$ e $\mathrm{Q}$, chegando-se à adaptação do quadro:

\begin{tabular}{|l|l|l|}
\cline { 2 - 3 } \multicolumn{1}{c|}{} & PRIMÁRIA & SECUNDÁRIA \\
\hline PARATAXE & 1P (inicial) & 2Q (continuação) \\
\hline HIPOTAXE & $\alpha \mathrm{P}$ (dominante) & $\beta \mathrm{Q}$ (dependente) \\
\hline
\end{tabular}

Como mencionado, propõe-se que os usos interproposicionais de assim distribuam-se ao longo de um continuum, configurado entre aqueles considerados representativos de um e de outro tipo de interdependência. Partiremos, portanto, dos considerados exemplares de relações do domínio da parataxe até os exemplares de relações do da hipotaxe, passando pelos que estão em meio do caminho. Nessa construção metodológica, localizaremos, pontualmente, o slot ocupado pelo Padrão B, focalizado aqui. 
Nos usos de assim na locução assim como apresentam-se quatro comportamentos semântico-formais, em que a locução exerce função (i) aditiva; (ii) comparativa correlativa; (iii) comparativa não-correlativa e (iv) conformativa. Dentre esses comportamentos, dois tipos de relações e de interdependência entre as orações articuladas pela locução podem ser observados.

No primeiro, assim como aditivo é utilizado em orações de mesmo estatuto, i. é, livres e funcionalmente independentes. Em 2Q, assim como representa uma extensão do significado de $1 \mathrm{P}$ a partir do acréscimo de algo novo, representativo de uma adição, que não implica nenhuma relação causal ou temporal entre as orações. Nesse caso temos, segundo Halliday (1985, p.207), a combinação da extensão com parataxe, resultando na co-ordenação entre orações $(1 \mathrm{P}+2 \mathrm{Q})$. Como se trata de uma adição neutra, mesmo dentro da interdependência paratática, há liberdade de sequenciação/ordenação entre 1P e $2 \mathrm{Q}$, possibilitando a inversão da ordem dessas orações, como exemplificado em (31):

(31) [...] Desejo sin- | cèramente que sua saude se tenha refeito com a volta ao $\mid$ clima em que o seu corpo foi criado, assim como desejo | que sua distinguida família se encontre bem[...] [FFXX-52b/119]

Assim como coordena as estruturas de natureza completiva de P e Q no interior da mesma proposição, sendo parafraseável por e também. Trata-se, portanto, de um valor aditivo que expressa inclusão, assinalando que a informação veiculada pelos constituintes, sob seu escopo, em Q, deve ser acrescentada à informação expressa, em $\mathrm{P}$, como subparte de uma estrutura cumulativa mais ampla.

Nessa função, a integração entre P e Q é menor do que na de comparação, já que se trata de orações independentes. Em outras ocorrências desse tipo, verifica-se um compartilhamento maior de estruturas de P em Q (para além do SN Suj), no entanto, em nenhum dos casos, há alteração de quaisquer aspectos (por exemplo, flexões verbais) dos termos elípticos em Q, como observamos nos casos de comparação, o que demonstra ser esse entrelaçamento menos incisivo do que aquele.

A mesma locução, agora comparativa (não-)correlativa e conformativa, é utilizada em orações de estatutos diferentes, sendo uma considerada funcionalmente independente, (modificada) e outra funcionalmente dependente (modificadora): "o elemento modificador é dependente do modificado" 
(Halliday, 1985, p.195). Nessa configuração de interdependência hipotática, a locução representa uma relação de realce do significado de áP a partir do acréscimo de um significado de comparação/ conformidade dentro da categoria de modo apresentada por Halliday (1985, p. 211), em âQ. A combinação de realce com hipotaxe $(\alpha \mathrm{P} \times \beta \mathrm{Q})$ resulta no que é conhecido na gramática tradicional como "orações adverbiais".

Entretanto, no caso das comparativas (não-)correlativas, diferentemente do que se observa nas relações de realce dentro da hipotaxe e também na perspectiva tradicional, é impossível a inversão da ordem das orações envolvidas: os elementos são ordenados em dependência, caracterizando traço da hipotaxe, mas são dependentes também da sequência/ordenação, o que constitui traço da parataxe. Estamos diante de um caso em que o uso da locução não pode ser categoricamente classificado como hipotático, uma vez que ainda revela traços paratáticos. Também semanticamente percebe-se uma relação intrínseca entre adição e comparação, i. é, nos casos de realce dentro da hipotaxe pode haver persistência da acepção aditiva. As ocorrências (32) e (33) ilustram as comparações correlativa e não-correlativa, respectivamente:

(32) eaSSi por mais que os queira ReduZir ao gremio deSSua igre| ja por velos taõ derramados: ConSsigo poCo fruto aSSim por alguñs | fugirem deSSua aldea; Como outros Sonegados de quem ostem. [AIXVIII-03/41]

(33) Meu presado Professor Fidelino | Meus pais muito estimam que o senhor | esteja melhor, assim como esta sua ami- | guinha que sempre o recorda com sal- | dade! [FFXX-54f/135]

Por outro lado, as conformativas comportam-se prototipicamente nas relações de realce dentro da hipotaxe: os elementos são dependentes, mas a ordem das orações não é determinante. Nesses casos, a relação entre essa acepção e as outras, constatadas nos demais usos da locução, pauta-se no traço modal de assim:

(34) No artigo - Insomnia - que hoje publicamos vem uma censura á Camara Municipal por não ter dado aos providenciais precisas para o dessecamento do tanque do Zunega, visto que pelo Excelentíssimo Governo da Provincia ja lhe forão presentes os planos e orçamentos d'aquela obra, assim como necessaria para a mesma obra. | |[LRXIX-495/99] 


\section{Considerações finais}

O referido continumm parataxe $>$ hipotaxe dos usos juntivos de assim pode ser caracterizado conforme o quadro que segue:

\begin{tabular}{|c|c|c|c|c|}
\hline $\begin{array}{c}\text { assim como } \\
\text { ADITIVO }\end{array}$ & $\begin{array}{c}\text { assim } \\
\text { CONCLUSIVO }\end{array}$ & $\begin{array}{c}\text { mesmo assim } \\
\text { CONTRASTIVO }\end{array}$ & $\begin{array}{c}\text { assim como } \\
\text { COMPAim como / assim que } \\
\text { CONFOR MATIVO / TEMPOR AL }\end{array}$ \\
\hline \hline P A R A T A X E & H I P O T A X E \\
\hline
\end{tabular}

Quadro 2 - Continuum parataxe > bipotaxe

De forma geral, ressaltamos o fato de que, embora em relações lógicosemânticas que revelam graus de complexidade distintos, as locuções e o juntor observados nesse continuum encontram-se em padrões sintáticos contíguos, (III) e (IV) (cf. Quadro 1). Esse dado mostra que a relação marcada na classificação fornecida a partir do cruzamento proposto por Raible confirma a constatação realizada a partir da análise sobre os pressupostos de Halliday, de que há uma forte fluidez dos padrões dessas construções, i. é, a contiguidade dos padrões sintáticos reflete a contiguidade entre parataxe e hipotaxe observada no continuum. Além disso, os usos que se enquadram nos padrões lógico-semânticos mais complexos, tais como contrastividade, revelam influências de padrões menos complexos, como causa/ condição, em relação ao Padrão de mesmo assim.

Especificamente em relação ao Padrão B - P assim como Q, algumas observações podem ser feitas a partir desse continuum:

(i) a locução juntiva assim como conformativa, apresentada no extremo direito do continuum, representa o esquema mais indicativo, juntamente com o Padrão assim que temporal, das relações hipotáticas;

(ii) as locuções juntivas assim como e assim que que se localizam mais à direita desse continuum, especificamente no padrão sintático (IV), o mais elevado para os casos sob observação, encontram-se em padrões lógico-semânticos menos complexos, modo e tempo, respectivamente; inversamente, a locução mesmo assim e o juntor assim, que se localizam mais à esquerda desse continum, especificamente no padrão sintático (III), encontram-se em padrões lógico-semânticos bem mais complexos, como é o caso das relações conclusivas e contrastivas;

(iii) a locução juntiva assim como comparativa (não)correlativa, apresentada no ponto médio do continuum representa o esquema mais indicativo da fluidez de 
traços da parataxe e da hipotaxe, uma vez que, embora localizada no domínio hipotático das relações e interdependências, apresenta traços formais da parataxe, tais como a impossibilidade de inversão sintática. ${ }^{16}$

(iv) a locução juntiva assim como aditiva representa, no ponto mais à esquerda desse continuum, esquema indicativo das relações paratáticas, embora também represente, já nesse ponto inicial, contextos semântico-cognitivas e formais que permitem ambiguidade entre comparação e adição.

\section{Bibliografia}

BARBOSA, A.; LOPES, C. (2002) Cartas de leitores e de redatores. Cópia digital.

(2006) Críticas, queixumes e bajulações na Imprensa Brasileira do século XIX: cartas de leitores. Rio de Janeiro: UFRJ, Pós-Graduação em Letras Vernáculas; FAPERJ.

HALLIDAY, M. A. K. (1985) Above the clause: the clause complex. In. __ An introduction to Funcional Grammar. New York: Arnold.

HALLIDAY, M. A. K.; HASAN, R. (1976) Cohesion in English. London, Longman.

HASPELMATH, M.; BUCHHOLZ, O. (1998) Equative and simulative constructions in the languages of Europe. In. VAN DER AUWERA; DÓNALL P. Ó. BAOILL (eds.). Adverbial constructions in the languages of Europe. Berlin/New York: Mouton de Gruyter, p. 277-334.

KABATEK, J. (2005) Tradiciones discursivas y cambio lingüístico. Lexis XXIX. 2, p. 151-177. NEVES, M. H. M. N. (2000) Gramática de usos do português. São Paulo: Editora Unesp.

RAIBLE, W. (2001) Linking clause. In. HASPELMATH et al. Language Typology and Language Universals. Berlin e New York: Walter de Gruyter, Vol 1, p.590-617.

SIMÕES, J. S; KEWITZ, V. (2006) Cartas paulistas dos séculos XVIII e XIX: uma contribuição para os corpora do PHPB. São Paulo: Humanitas/FFLCH/USP.

TRAUGOTT, E. (2003) Constructions in Grammatizalization. In: JOSEPH, B.; JANDA, R. D. (orgs). The handbook of historical linguistics. Oxford: Blackwells.

(1995) The role of the development of discourse markers in a theory of grammaticalization. Paper presented at ICHL XII, Manchester. Disponível em: http:// www.stanford.edu/ traugott/traugott.html. Acesso em: 20/02/2004.

. (1989) On the rise of epistemic meanings in English: an example of subjectivication in semantic change. Language 65:31-55.

. (1982) From propositional to textual and expressive meanings: some semanticpragmatic aspects of grammaticalization. In: LEHMMAN, W.; MALKIEL, Y. (eds) Perspectives on historical linguistics. Amsterdam, John Benjamins, p. 245-271.

16 O Padrão imediatamente anterior, $\mathrm{P}$ mesmo assim Q, também caracteriza tal fluidez, mas, agora, de aspectos semântico-cognitivos, já que sua semântica contrastiva permite interpretá-lo com uma acepção que revela traços concessivos, tradicionalmente identificados no âmbito da hipotaxe. 
TRAUGOTT, E; KÖNIG, E. (1991) The semantic-pragmatics of grammaticalization revisited. In: TRAUGOT'T, E.; HEINE, B. (eds.) Approaches to grammaticalization. Vol. 1. John Benjamins Publishing Company.

TRAUGOTT, E.; HEINE, B. (1991) Approaches to grammaticalization. Vol. 1. John Benjamins Publishing Company. 